\title{
Уровень добычи нефти как фактор роста экономики Арктики (США, Аляска)
}

С.В. БEКАРЕВА, кандидат экономических наук, Новосибирский национальный исследовательский государственный университет. E-mail: s.bekareva@mail.ru

Е.Н. МЕЛЬТЕНИСОВА, кандидат экономических наук, Новосибирский национальный исследовательский государственный университет, Институт экономики и организации промышленного производства СО РАН. E-mail: emeltenisova@gmail.com

А. ГЕРРЕЙРО, Новосибирский национальный исследовательский государственный университет, Новосибирск

Аннотация. Задачей настоящего исследования было оценить, насколько фактор энергетических ресурсов территории, который мы связали с темпами роста добычи нефти в Арктическом регионе США, влияет на экономический рост штата Аляска. Методология исследования опирается как на классические модели экономического роста, так и на их модификацию, учитывающую энергоресурсный фактор. Для оценки предложенной модели была использована векторная модель коррекции ошибок. В краткосрочном периоде эмпирически было подтверждено влияние классических факторов труда и капитала на экономический рост региона. Также значимыми факторами явились показатель энергетических ресурсов региона и индикатор технологического развития. Настоящее исследование служит подтверждением важности развития добывающей отрасли в штате Аляска в плане развития как в целом экономики региона, так и инфраструктуры, роста занятости населения, благосостояния и социального развития.

Ключевые слова: Арктика; Аляска; энергетические ресурсы; векторная модель коррекции ошибок

\section{Введение}

Арктика - специфический регион, богатый природными ресурсами, но отличающийся суровым климатом и сложными условиями для ведения бизнеса. Арктическое побережье имеет большой потенциал для реализации инвестиционных проектов в области разработки и освоения шельфовых месторождений углеводородов, которые в перспективе могут создать все условия для экономического роста прилегающих и материковых территорий (Novoselov et al., 2017).

Это верно не только для России, но и, например, для США, единственный арктический штат которых - Аляска-представляет собой одну из богатейших энергетическими ресурсами территорий страны. 
На сегодняшний день имеется достаточное количество исследований влияния добычи энергоресурсов на экономический рост как таковой, но применительно к арктическим регионам эмпирических оценок, подтверждающих эту взаимосвязь, явно недостаточно. В научной литературе в основном описываются проблемы, сопряженные с освоением Арктики: значительные затраты на транспортировку добытых ресурсов, повышенные риски, расходы и сроки разработки месторождений, в том числе связанные с политикой регулирования территорий, защиты окружающей среды (Budzuk, 2009; Gulas et al., 2017). Анализируются проблемы с эксплуатацией инфраструктурных объектов, рабочей силы, сложности с общими условиями работы, a также налогообложением и регулированием бизнеса [Avango et al., 2014]. Эмпирических оценок влияния разработки арктических месторождений на экономический рост ни в российских, ни в зарубежных источниках нам найти не удалось. Между тем они позволили бы обосновать целесообразность дальнейшего освоения и инвестирования с этой целью арктических шельфов.

Чтобы оценить, как темпы роста нефтедобычи на месторождениях Северной Аляски влияют на экономический рост штата, мы опирались как на классические модели экономического роста, так и на их модификацию, учитывающую фактор добычи энергетических ресурсов. Для анализа рассматриваемых зависимостей была использована векторная модель коррекции ошибок (VECM).

Коль скоро качество эконометрического анализа сильно зависит от полноты и достоверности статистических данных, мы при проведении наших расчетов рассматривали главным образом опыт США, обладающих достаточной и качественной статистической базой (Bekareva et al., 2018).

Эмпирически было подтверждено влияние классических факторов (труда и капитала) на экономический рост региона в долгосрочной перспективе, а также прямая зависимость темпа роста доходов региона от добычи нефтяных ресурсов (как в краткосрочном, так и долгосрочном периодах). При этом фактор энергетических ресурсов оказался значим в уравнении экономического роста только для краткосрочной перспективы. Мы полагаем, что влияние этой переменной на долгосрочный экономический рост является опосредованным, через параметр инвестиций в основной капитал. 


\section{Роль энергоресурсов как фактор экономического роста}

Согласно классическим теориям, факторами экономического роста выступают трудовые ресурсы, капитал и технологический прогресс. При этом констатируется, что рост экономики страны всегда сопровождается ростом потребления различных видов энергоресурсов, в то время как существует и обратная зависимость, когда рост энергопотребления, а также инвестиции в передовые технологии в энергетике создают условия для стабильного роста экономики в будущем.

Эмпирическому подтверждению значимости энергоресурсов для экономического роста территории посвящено достаточное количество научных исследований (см., к примеру [Tiba, Omri, 2017]). Но при анализе экономических показателей исследователи часто сталкиваются с тем, что большинство из них имеют общий тренд, который препятствует определению истинной взаимосвязи факторов. Для решения этой проблемы в эконометрике в последние годы применяется подход, основанный на построении коинтеграционного вектора и включения его параметров в процесс оценки влияния показателей.

Коинтеграционный вектор - это линейная комбинация экономических показателей, которая не имеет тренда на повышение или снижение, ее изменения происходят около определенного значения. К примеру, при росте показателей ВВП и объема инвестиций попытка оценить влияние одной величины на другую неизбежно оборачивается сравнением обоих трендов. Но можно подобрать такую линейную комбинацию ВВП и уровня инвестиций, которая будет практически постоянна в любой момент времени. Поиск такой комбинации и носит название коинтеграции. Этот метод находит отражение в векторных моделях коррекции ошибки (VECM) (Wang et al., 2011).

Кроме того, отмечено, что экономические показатели нередко влияют друг на друга с некоторым лагом, к примеру, ВВП реагирует на рост инвестиций с лагом не менее чем в один год, когда экономика ощущает эффект от верных инвестиционных решений. В связи с этим уместно включать в исследование экономические показатели не только данного, но и предшествующих периодов времени (модели авторегрессии VAR) (Fallahi, 2011). Главное при этом - правильно определить глубину лага. 
Для того чтобы учесть и лаги переменных, и коинтеграцию, в экономической литературе рассматривают методы коинтеграции авторегрессии с распределенным лагом (ARDL) (Shahbaz et al., 2013). Все перечисленные методы активно используются для оценки факторов экономического роста как для развитых, так и развивающихся стран.

\section{Метод исследования}

В своем исследовании мы опирались на модифицированную классическую модель Солоу (1956), где основными факторами, определяющими экономический рост, являются капитал, труд и технологический прогресс. В нашем случае, согласно идеям Мальтуса (1978), в модели учитывается также фактор энергетических ресурсов, а именно - показатель уровня их добычи в регионе. Поскольку ресурсы, о которых идет речь, практически полностью потребляются в национальной экономике, с нашей точки зрения, показатель их добычи может быть использован для анализа экономического роста как на уровне экономики в целом, так и отдельно региона добычи.

Гипотеза, которую мы проверяем эмпирически с использованием предложенной модели, заключается в наличии положительного влияния уровня добычи нефти на темп роста валового регионального продукта (ВРП) в долгосрочном периоде. Также проводится исследование характера влияния факторов экономического роста на ВРП в краткосрочной перспективе.

Модель, предложенная для целей настоящего анализа, имеет следующий вид:

$$
\begin{aligned}
& Y(t)=K(t)^{a} R(t)^{\beta}[A(t) L(t)]^{1-a-\beta} \\
& a>0, \beta>0, a+\beta>1,
\end{aligned}
$$

где: $\mathrm{Y}(\mathrm{t})$ - уровень производства в стране или регионе;

$\mathrm{K}(\mathrm{t})$ - уровень капитала;

$\mathrm{R}(\mathrm{t})$ - объем добытых и потребленных энергетических ресурсов;

$\mathrm{L}(\mathrm{t})$ - число занятых;

$\mathrm{A}(\mathrm{t})$ - технологическая компонента.

Согласно уравнению (1), рост ВВП (уровня производства) обеспечивается физическим капиталом (количеством и качеством основных фондов); трудовыми ресурсами (количеством занятых) и фактором технологического прогресса, который, как 
правило, заданная величина. Мы включили в него также ресурсный фактор, считая, что при прочих равных условиях, чем больше ресурсов в экономике, тем выше уровень производства они могут обеспечить.

Для того, чтобы выявить причинно-следственные связи, мы те же данные, что были использованы в уравнении (1), представили в приростных показателях. На основе уравнения (2), демонстрирующего изменение темпов роста исследуемых показателей, был проведен анализ долгосрочной зависимости между темпом роста экономики штата Аляска и энергетическими ресурсами зоны Арктики.

$$
g_{y}(t)=a g_{k}(t)=\beta g_{R}(t)+(1-a-\beta)\left[g_{A}(t)+g_{L}(t)\right],
$$

где: $\mathrm{K}$ - совокупные инвестиции федерального правительства США в Аляску, млрд долл. Мы предполагаем, что в условиях равновесия инвестиции направляются на прирост капитала в штате, при этом $g_{k}$ рассчитывается как годовой темп роста инвестиций. Использование в качестве регрессора показателя уровня частных инвестиций не представляется возможным из-за отсутствия информации, кроме того, мы предполагаем, что из-за высокой неопределенности арктические проекты во многом будут реализовываться с участием государства (в том числе и через государственно-частное партнерство), что оправдывает использование показателя государственных инвестиций в уравнении (2).

$\mathrm{L}$ - количество занятых в модели $g_{L}$ представляет собой годовой темп роста трудовых ресурсов в штате Аляска.

А - количество патентов в США. В статистических источниках нет отдельных данных по количеству патентов для Аляски, однако мы руководствовались предположением, что темп технологического прогресса в отдельном штате максимально приближен к динамике этого показателя в стране в целом. Данное предположение аналогично гипотезе, использованной в работе Мэнкью и других (1987), где авторы показали, что темпы технологического прогресса практически одинаковы для большой выборки различных стран мира. В нашем случае мы принимаем постоянство темпа роста технологического прогресса не по всему миру, а только по отдельному государству. В модели $g_{A}$ годовой темп роста числа патентов в штате Аляска, который равен этому показателю для США. 
$\mathrm{R}$ - фактор энергетических ресурсов, который рассчитывается как отношение добытой нефти в регионе Северная Аляска к общему ее объему, добытому в штате Аляска, в день в среднем за год. Таким образом, учитывая, что регион Северной Аляски практически полностью расположен на шельфе Арктики, расчет доли добычи в данном регионе позволит оценить роль объема добычи в Арктической зоне страны в экономическом росте штата Аляска. В оцениваемой модели $g_{R}-$ годовой темп роста доли добытой нефти в районе Арктики в общем объеме добытой нефти на Аляске.

Y - валовый региональный продукт (ВРП) Аляски, $g_{Y}$ - годовой темп роста ВРП Аляски.

\section{Полученные результаты}

Для эмпирической оценки предложенной модели были собраны статистические данные по показателям, охватывающим период с 1976 по 2016 гг., в расчетах использованы годовые данные. Их источником послужили данные агентств State Energy Data System (SEDS), U.S. Energy Information Administration's (EIA) ${ }^{1}$. Описательная статистика показателей представлена в таблице 1 .

\section{Таблица 1. Средние значения рассматриваемых показателей в 1976-2016 гг.,\%}

\begin{tabular}{|l|c|c|c|c|}
\hline \multicolumn{1}{|c|}{ Параметр } & $\mathbf{1 9 7 6 - 1 9 8 9}$ & $\mathbf{1 9 9 0 - 2 0 0 0}$ & $\mathbf{2 0 0 1 - 2 0 1 0}$ & $\mathbf{2 0 1 1 - 2 0 1 6}$ \\
\hline Темп роста ВРП & 1,12 & 1,98 & 7,45 & $-0,93$ \\
\hline Темп роста инвестиций & н/д & 15,71 & 28,48 & 4,59 \\
\hline Темп роста занятых & 0,47 & 0,67 & 1,26 & $-0,07$ \\
\hline Темп роста числа патентов в США & $-5,18$ & $-9,09$ & $-4,63$ & $-3,71$ \\
\hline $\begin{array}{l}\text { Доля добытой нефти на месторо- } \\
\text { жденияхСевернойАляскив общем } \\
\text { объеме нефти в штате Аляска }\end{array}$ & 93,18 & 94,47 & 97,66 & 97,28 \\
\hline
\end{tabular}

Из таблицы 1 видно, что темп роста экономики Аляски сильно замедлился в 2011-2016 гг., как и темп роста инвестиций в этот штат. Отрицательный темп роста по патентам, на наш взгляд, объясняется тем, что в последние годы США в большей степени занимаются покупкой готовых идей и малых стартапов, чем развитием технологий «под ключ».

${ }^{1}$ The State Energy Data System (SEDS), the U. S. Energy Information Administration's (EIA), URL: https://www.eia.gov/state/seds/ (accessed 15.12.2017). 
Таблица 2 представляет результаты оценивания параметров с помощью векторной модели коррекции ошибок, что позволило нам сделать вывод о наличии краткосрочных взаимосвязей. Данный метод позволяет констатировать влияние каждого параметра уравнения (инвестиций, числа занятых, числа патентов и доли добычи нефти в Арктике) на все остальные переменные в краткосрочном периоде, а также оценить силу этого влияния.

\section{Таблица 2. Результаты оценки параметров VECM} в краткосрочном периоде

\begin{tabular}{|l|c|l|c|l|l|}
\hline Perpeccopы & $\boldsymbol{g}_{y}(t)$ & $g_{k}(t)$ & $g_{R}(t)$ & $g_{A}(t)$ & $g_{L}(t)$ \\
\hline \multirow{2}{*}{$g_{y}(t)(-1)$} & $0,912^{\star \star}$ & 0,35 & $-0,11$ & 0,02 & $0,07^{\star \star}$ \\
\hline \multirow{2}{*}{$g_{k}(t)(-1)$} & $(6,86)$ & $(0,38)$ & $(-0,78)$ & $(0,55)$ & $(2,41)$ \\
\hline \multirow{2}{*}{$g_{R}(t)(-1)$} & $0,112^{\star \star}$ & 0,09 & $-0,06$ & $0,07^{\star \star}$ & $-0,05^{\star \star}$ \\
\hline \multirow{2}{*}{$g_{A}(t)(-1)$} & $(1,98)$ & $(0,23)$ & $(-0,88)$ & $(3,23)$ & $(4,58)$ \\
\hline \multirow{2}{*}{$g_{L}(t)(-1)$} & $0,34^{\star \star}$ & $0,15^{\star \star}$ & $-0,49$ & $-2,34^{\star \star}$ & $0,59^{\star \star}$ \\
\hline \multirow{2}{*}{ Constant } & $(4,21)$ & $(2,15)$ & $(-0,54)$ & $(-7,53)$ & $(2,74)$ \\
\hline $\mathrm{R}^{2}$ & $1,49^{\star \star}$ & $2,897^{\star}$ & $-0,02$ & $0,711^{\star \star}$ & $0,19^{\star \star}$ \\
\hline$\chi^{2}$ & $(6,83)$ & $(1,89)$ & $(-0,1)$ & $(8,53)$ & $(4,25)$ \\
\hline & $4,38^{\star \star}$ & $3,33^{\star \star}$ & 0,78 & $1,91^{\star \star}$ & $-0,45^{\star \star}$ \\
& $(4,1)$ & $(4,14)$ & $(0,65)$ & $(4,87)$ & $(-2,7)$ \\
\hline & $-0,02^{\star \star}$ & $-0,02$ & $-0,02$ & $0,004^{\star}$ & $-0,05^{\star \star}$ \\
& $(-4,26)$ & $(-0,52)$ & $(-0,25)$ & $(1,78)$ & $(3,17)$ \\
\hline & 87,68 & 86,40 & 87,766 & 88,64 & 41,21 \\
\hline
\end{tabular}

Примечание: **, * - значимость при 5\%- и 10\%-х уровнях значимости соответственно; в скобках указаны уровни значимости коэффициентов (t-statistics).

В первой строке таблицы представлены зависимые переменные. То есть сначала мы определили, какие факторы влияют на темп роста ВВП $\left(g_{y}(t)\right)$ (темпы роста капиталов, ресурсов, технологического прогресса), затем - что оказывает влияние на эти факторы (регрессоры из первого столбца). Все факторы рассмотрены с лагом в один период.

Как показали наши расчеты, в краткосрочной перспективе на темпы роста ВРП Аляски положительно влияют все рассмотренные в модели факторы.

Влияние факторов рабочей силы, капитала и технологического прогресса полностью согласуется с неоклассической моделью экономического роста Солоу: чем больше трудовых и капитальных ресурсов в регионе, чем выше уровень технологического прогресса, тем выше темп роста экономики штата. 
Фактор энергетических ресурсов (темп роста доли добычи нефти в Северной Аляске в общем объеме нефтедобычи штата) тоже оказался весьма значим для экономики: чем больше добыча в регионе, тем выше темп экономического роста.

Мы также обнаружили, что в краткосрочном периоде на переменную капитала, характеризующую темп роста инвестиций, влияют факторы технологического прогресса, рабочей силы, фактор энергоресурсов. Полученная оценка коинтеграционного вектора для переменной капитала свидетельствует о перенасыщенности инвестициями экономики данного региона ${ }^{2}$. В данном случае мы подразумеваем, что в развитие штата Аляска вкладывается несколько больше, чем требуется. В будущем данный показатель будет корректироваться в направлении долгосрочного равновесия, величина инвестиций в штат будет сокращаться.

Добыча нефти в Северной Аляске является важным фактором экономического развития штата, о чем свидетельствуют эмпирические оценки модели: выявлена значимость данной переменной во всех построенных уравнениях регрессии. Оценки показывают, что темп роста добычи нефти положительно влияет как на динамику занятости, снижая безработицу (рост добычи энергоресурсов на $1 \%$ обеспечивает рост занятых на $0,59 \%$ ), так и на темп роста инвестиций (рост добычи энергоресурсов на $1 \%$ способствует росту инвестиций в основной капитал на $0,15 \%$ ). Это характеризует развитие компаний добывающего сектора и сопутствующей инфраструктуры.

Кроме того, наши расчеты показали, что рост добычи энергоресурсов в Арктике положительно влияет на темпы экономического роста: при увеличении добычи нефти на $1 \%$ ВРП штата вырастает на $0,34 \%$. Таким образом, факт значимости разработки энергоресурсов и их добычи для экономического развития региона можно считать подтвержденным на практике. Кроме прямого положительного влияния, мы выявили также и опосредованное воздействие динамики добычи на темпы роста ВРП - за счет

\footnotetext{
${ }^{2}$ Коинтеграционный вектор отражает равновесное состояние, в направлении которого экономические показатели стремятся в каждом рассматриваемом периоде. В случае, если коэффициент перед переменной является положительным, принято считать, что в краткосрочном периоде данный показатель находится выше своего равновесного уровня, если отрицательным - ниже. Параметры вектора определяются линейной комбинацией регрессоров уравнения, которая, в свою очередь, является стационарной.
} 
стимулирования инвестиционного спроса и спроса на трудовые ресурсы.

При этом нужно подчеркнуть, что на основе примененного уравнения мы можем сделать вывод о значимости ресурсов Арктики исключительно для штата Аляска в США. Применить данные выводы для других стран не представляется возможным по причине отсутствия статистических данных по уровню добычи, инвестиций и показателей освоения арктических территорий. В случае наличия статистических данных будет возможно применить описанную методологию оценки влияния добычи арктических ресурсов на экономику регионов других стран и сопоставить результаты, которые, очевидно, будут отражать влияние страновых особенностей (таких как состояние институциональной среды в отрасли, система налогообложения и т.д.).

\section{Литература/References}

Andreassen, N. (2016). Arctic energy development in Russia - How "sustainability" can fit? Energy Research \& Social Science. No. 16. Pp. 78-88.

Avango, D., Hacquebord, L., Wråkberg, U. (2014). Industrial extraction of Arctic natural resources since the sixteenth century: technoscience and geo-economics in the history of northern whaling and mining. Journal of Historical Geography. No. 44. Pp. 15-30.Bekareva, S.V., Meltenisova, E.N., Guerreiro, A. (2018). Arctic Energy Resources as an Economic Growth Factor: Evidence from Alaska, USA. International Journal of Energy Economics and Policy. No. 8(4). Pp. 1-12.

Budzuk, Ph. (2009). Arctic Oil and Natural Gas Potential. U.S. Energy Information Administration Office of Integrated Analysis and Forecasting Oil and Gas Division. Available from: http:/www.eia.gov/oiaf/analysispaper/arctic/pdf/ arctic oil.pdf

Fallahi, F. (2011). Causal relationship between energy consumption (EC) and GDP: a Markov-switching (MS) causality. Energy. No. 36. Pp. 4165-4170.

Gulas, S., Downton, M., D’Souza, K., Hayden, K., Walker, T.R. (2017). Declining Arctic Ocean oil and gas developments: Opportunities to improve governance and environmental pollution control. Marine Policy. No. 75. Pp. 53-61.

Malthus, Th.R. (1978). An Essay on the Principle of Population, as It Affects the Future Improvement of Society. L.: J. Johnson, 125 p.

Mankiw, N.G., Miron, J.A., Weil, D.N. (1992). A Contribution to the Empirics of Economic Growth. Quarterly Journal of Economics. No. 107. Pp. 407-437.

Novoselov, A., Potravny, I., Novoselova, I., Gassiy, V. (2017). Selection of priority investment projects for the development of the Russian Arctic. Polar Science. Available from: http://dx.doi.org/10.1016/j.polar.2017.10.003

Shahbaz, M., Ozturk, I., Afza, T., Ali A. (2013). Revisiting the environmental Kuznets curve in a global economy. Renew Sustain Energy Rev. No. 25. Pp. 494-502.

Solow, R.M. (1956). A Contribution to the Theory of Economic Growth. Quarterly Journal of Economics. No. 70. Pp. 65-94. 
Tiba, S., Omri, A. (2017). Literature survey on the relationship between energy, environment and economic growth. Renewable and Sustainable Energy Reviews. No. 69. Pp. 1129-1146.

Wang, Y., Wang, Y., Zhou, J., Zhu, X., Lu, G. (2011). Energy consumption and economic growth in China: a multivariate causality test. Energy Policy. No. 39. Pp. 4399-4406.

Статья поступила 11.04.2019.

Для цитирования: Бекарева С.В., Мельтенисова Е.Н., Геррейро А. Уровень добычи нефти как фактор роста экономики Арктики (США, Аляска)// ЭКО. 2019. № 9. C. 155-164. DOI: 10.30680/ECO0131-7652-2019-9-155-164.

For citation: Bekareva, S.V., Meltenisova, E.N., Guerreiro, A. (2019). The Level of Oil Production as a Growth Factor in the Arctic Economy (USA, Alaska). ECO. No. 9. Pp. 155-164. (In Russ.). DOI: 10.30680/ECO0131-7652-2019-9-155-164.

\section{Summary}

Bekareva, S.V., Cand. Sci. (Econ.), Novosibisrk State University, Meltenisova, E.N., Cand. Sci. (Econ.), Institute of Economics and Industrial Engineering, SB RAS, Novosibirsk State University, Guerreiro, A., Novosibirsk State University, Novosibirsk

The Level of Oil Production as a Growth Factor in the Arctic Economy (USA, Alaska)

Abstract. The objective of our study was estimating how the factor of the region's energy resources, which we have attributed to the oil production growth rates on the Alaska North Slope, affects the economic growth of Alaska. The study methodology is based on both classical models of economic growth and their modification considering the factor of energy resources. A vector error correction model (VECM) was used for the purpose of our investigation. The influence of classical factors, labor and capital, on economic growth of the region in the short-term perspective has been empirically proven. Other factors such as energy resources and technological progress are also significant. Our investigation proves that oil industry development is the key factor of economic growth of the Arctic region in the USA. Development of the oil and gas production sector in Alaska attracts investment into the business of oil and gas production and infrastructure companies and creates jobs for the local population.

Keywords: Arctic region; Alaska; energy resources; economic growth; vector error correction model (VECM) 